\title{
Enantioselective Supramolecular Carriers for Nucleoside Drugs. A Thermodynamic and Kinetic Gas Phase Investigation
}

\author{
Caterina Fraschetti, ${ }^{1}$ Antonello Filippi, ${ }^{1}$ Maria Elisa Crestoni, ${ }^{1}$ Claudio Villani, ${ }^{1}$ \\ Graziella Roselli, ${ }^{2}$ Stefano Levi Mortera, ${ }^{1}$ Maurizio Speranza ${ }^{1}$ \\ ${ }^{1}$ Chimica e Tecnologie del Farmaco, Facoltà di Farmacia, Sapienza University of Rome, Rome, Italy \\ ${ }^{2}$ Scienze Chimiche, Facoltà di Chimica, University of Camerino, Rome, Italy
}

\begin{abstract}
The enantioselective interactions between chiral tetra-amidic receptors and nucleosides have been investigated by the ESI-IT-MS and ESI-FT-ICR-MS methodologies. Configurational effects on the CID fragmentation of diastereomeric $\left[M^{\mathrm{H}}{ }_{2} \bullet \mathrm{H} \bullet A\right]^{+}$aggregates $\left(\mathrm{A}=2^{\prime}\right.$-deoxycytidine $\mathbf{~ d C}$, citarabine (ara-C) were found to be mostly offset by isotope effect in $\left[\boldsymbol{S}^{\mathbf{X}}{ }_{2} \bullet \mathrm{H} \cdot \mathrm{A}\right]^{+}(\mathrm{X}=\mathrm{H}, \mathrm{D})$ differently from the results obtained on the analogues $(A=$ cytidine $\mathbf{C}$ and gemcitabine $\mathbf{G})$. This result points the involvement of two different nucleoside/tetraamide isoforms. The structural differences of the $\left[\boldsymbol{M}^{\mathrm{H}}{ }_{2} \bullet \mathrm{H}^{\bullet} \mathrm{A}\right]^{+}(\mathrm{A}=\mathbf{C}$ and $\mathbf{G})$ complexes vs. the $\left[\boldsymbol{M}^{\mathrm{H}}{ }^{\circ}{ }^{\bullet} \mathrm{H} \bullet \mathrm{A}\right]^{+}(\mathbf{d C}$ and ara-C) ones is fully confirmed by the kinetics of their uptake of the 2-aminobutane enantiomers, measured by FT-ICR mass spectrometry. Indeed, uptake of the 2-aminobutane enantiomers by $\left[M^{H}{ }_{n} \bullet H \cdot A\right]^{+}\left(n=1,2 ; A=d C\right.$ and ara-C) complexes is reversible, while that by $\left[M^{H}{ }_{n} \bullet H \bullet A\right]^{+}$ $(\mathrm{n}=1,2 ; \quad \mathrm{A}=\mathbf{C}$ and $\mathbf{G})$ is not. The most encouraging result concerning the measured fragmentation and kinetic differences between $\mathbf{C}$ and ara-C, that are just epimers, indicates the possibility to subtly modulate the non-covalent drug/receptor interactions, through the electronic properties of the 2'-substituent on the nucleoside furanose ring, and furthermore on its three-dimensional position.
\end{abstract}

Key words: Enantioselectivity, Enantiodiscrimination, Gas-phase, FT-ICR mass spectrometry, LIT mass spectrometry, Nucleoside, Supramolecular selector, Kinetics, Diastereomeric discrimination

\section{Introduction}

$\mathrm{N}$ atural nucleosides and their 2'-deoxy derivatives are physiologic buildings blocks of RNA and DNA polymers, respectively, and play key roles in biological environment as neuromodulators. For instance, adenosine is an ubiquitous

Electronic supplementary material The online version of this article (doi:10.1007/s13361-012-0432-9) contains supplementary material, which is available to authorized users.

Correspondence to: Caterina Fraschetti; e-mail: caterina.fraschetti@uniroma1.it purine nucleoside essential in the regulation of cardiovascular physiological functions $[1,2]$. The therapeutic use of nucleosides analogs basically concerns chemotherapy. By acting as prodrugs, they can be phosphorylated in vivo to yield the relative nucleotides, which are the effective antimetabolite or "suicide" inhibitor, responsible of the termination in the synthesis of the DNAs and RNAs. Examples of pyrimidine nucleosides are cytarabine, natural product deriving from marine source [3], and gemcitabine. The observed resistance to the mentioned drugs is being attributed to the abundance and distribution of nucleoside transporters (NTs), but also to the specific structure-activity 
relationship between the transmembranes transporters and anticancer or antiviral nucleosides [4-7]. Furthermore, it is well known that the conformation of nucleosides may depend on 2'substituent electronegativity [8], and even the deviation from planarity of furanose ring may play a role in the recognition by NTs through the cell membrane.

The focus of the present paper is on the gas-phase investigation of the noncovalent interactions in the protonbound complexes between some physiological pyrimidine nucleosides and their analogues ( $\mathrm{A}$ in Chart 1), and the protonated tetramide $\mathrm{Y}_{2} \mathrm{~W}_{2}$-type receptors $\boldsymbol{M}^{\mathbf{X}}$ (Chart 1; $\mathrm{Y}=5$ methoxyisophtalic acid, W=1,2-diphenyldiammine, $\boldsymbol{M}=\boldsymbol{R}, \boldsymbol{S}$; $\mathrm{X}=\mathrm{H}, \mathrm{D})$. The latter display amphiphilic properties attributable to the presence of four amidic bonds (Figure 1). Previous mass spectrometric study [9], performed by us on noncovalent interactions in the proton-bound complexes between $\boldsymbol{M}^{\mathbf{X}}$ and some representative amino acids, indicated that $\boldsymbol{M}^{\mathbf{X}}$ may acquire different conformations in the gas phase by induced fit on complexation with the chiral aminoacidic guests. The gas phase investigation presented here is based on the application of two mass spectrometric approaches: the ESI-LIT mass spectrometry, to obtain some information on the relative stability of the diastereomeric $\left[\boldsymbol{M}^{\mathrm{X}} \cdot \mathrm{H} \cdot \mathrm{A}\right]^{+}$adducts by collision induced dissociation (CID) of the $\left[\boldsymbol{M}_{2}^{\mathbf{X}} \cdot \mathbf{H} \cdot \mathrm{A}\right]^{+}$aggregates, and the ESI-FT-ICR mass spectrometry, to investigate the kinetics of the gas phase reaction of the $\left[\boldsymbol{M}^{\mathbf{H}}{ }_{\mathbf{n}} \cdot \mathrm{H} \cdot \mathrm{A}\right]^{+}(\mathrm{n}=1,2)$ diastereoisomers toward a chiral amine. The use of labeled macrocycles in the CID experiments allows also to evaluate conceivable isotope effects on fragmentation. The purpose of this paper is to investigate the supramolecular effects induced

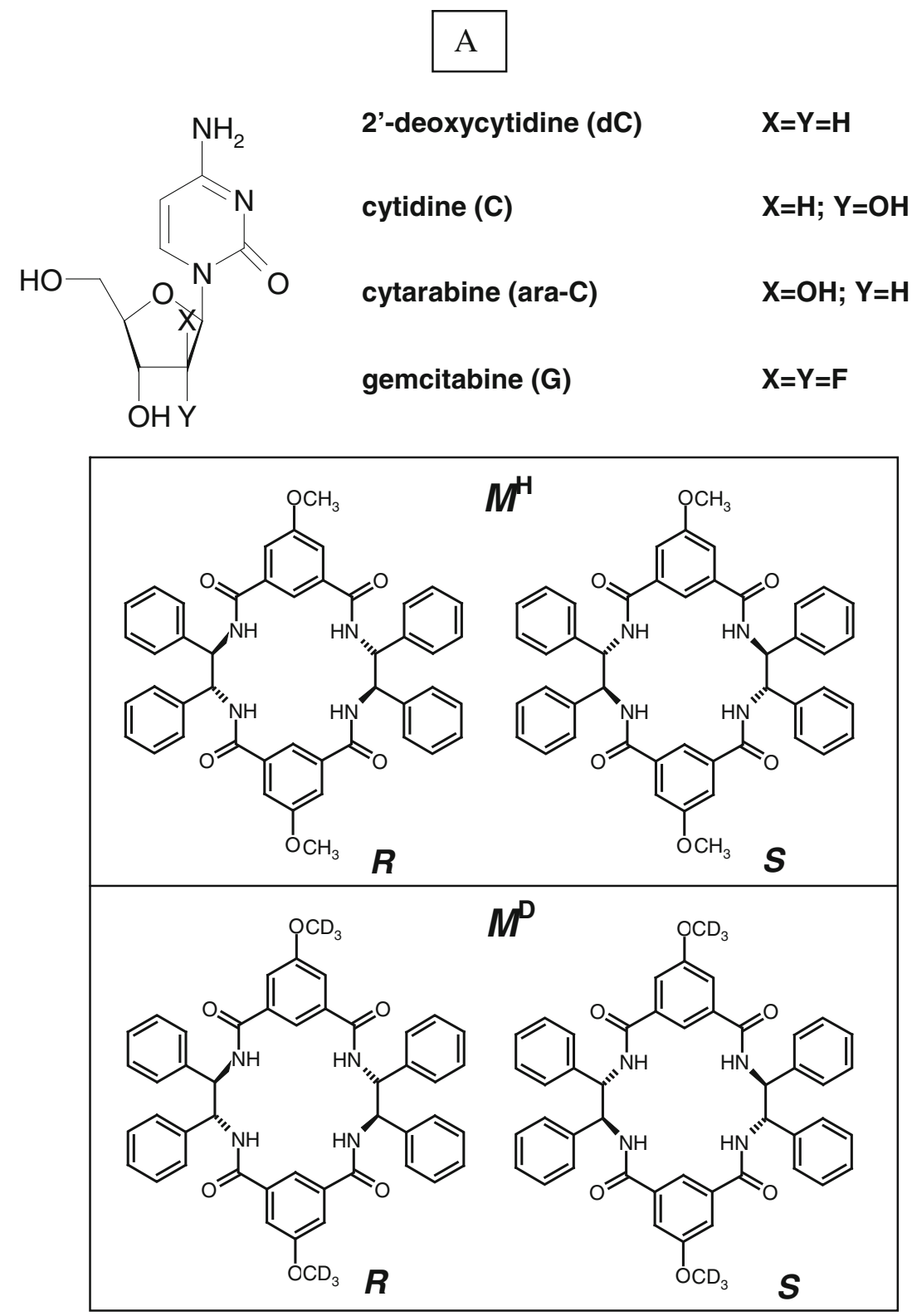

Chart 1. Selected chiral receptors $\boldsymbol{M}$ and nucleoside guests $A$ 


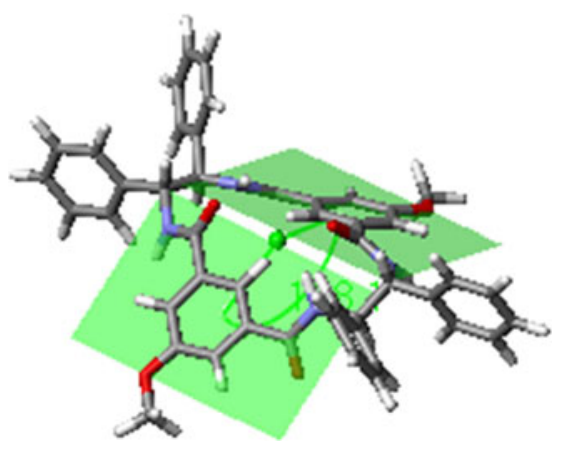

Figure 1. C2-symmetric saddle-roof structure of the selected tetramide receptor. Substituents on the stereogenic carbons are omitted for clarity

by the encapsulation of several pyrimidine nucleosides. Low pressure regime of the above gas-phase experiments excludes perturbing solvent and counterion effects, thus maximizing the noncovalent network effect on the structure and the reactivity of the selected proton-bound complexes.

\section{Materials and Methods}

Enantiomerically pure compounds $\boldsymbol{M}$ were synthesized and purified by established procedures $[10,11]$. The pure nucleosides dC, C, and ara-C were purchased from Sigma-Aldrich (Schnelldorf, Germany) and pure $\mathbf{G}$ from Aurora Fine Chemicals LLC (San Diego, CA, USA). Sigma-Aldrich provided the $(R)-(-)$ $\left(\mathrm{B}_{\mathrm{R}}\right)$ and $(S)-(+)-2$-butylamine $\left(\mathrm{B}_{\mathrm{S}}\right)$ as well.

\section{ESI-IT-MS Experiments}

The CID experiments on $\left[\boldsymbol{M}_{2}^{\mathbf{X}} \cdot \mathrm{H} \cdot \mathrm{A}\right]^{+}$adducts were performed on an LXQ-Finnigan (Milan, Italy) Linear Ion Trap mass spectrometer equipped with an electrospray ionization (ESI) source and a syringe pump. Operating conditions of the ESI source were as follows: ion spray voltage $=+4.0 \mathrm{kV}$; sheath gas $=$ 5 (arbitrary scale); sweep gas $=5$ (arbitrary scale); capillary temperature $=275{ }^{\circ} \mathrm{C}$. Equimolar methanolic solutions $\left(1 \times 10^{-}\right.$ ${ }^{4} \mathrm{M}$ ) containing two pseudo-enantiomers of the macrocycles (i.e., $\left[\boldsymbol{M}^{\mathbf{H}}\right] /\left[\boldsymbol{M}^{\mathbf{D}}\right]=1\left(\left[\boldsymbol{M}^{\mathbf{H}}\right] /\left[\boldsymbol{M}^{\mathbf{D}}\right]=\boldsymbol{R}^{\mathbf{H}} / \boldsymbol{S}^{\mathbf{D}}\right.$ or $\left.\boldsymbol{S}^{\mathbf{H}} / \boldsymbol{R}^{\mathbf{D}}\right)$, together with an amount of the nucleoside A $\left(2 \times 10^{-4} \mathrm{M}\right)$ were infused via a syringe pump into the ESI source at a flow rate of $5 \mu \mathrm{L} / \mathrm{min}$. ESI of the solutions leads to the formation of appreciable amounts of the corresponding proton-bound complexes (i.e., $\left[\boldsymbol{M}^{\mathbf{X}}{ }_{2} \cdot \mathrm{H} \cdot \mathrm{A}\right]^{+}$ and $\left.\left[\boldsymbol{M}^{\mathbf{H}} \cdot \boldsymbol{M}^{\mathbf{D}} \cdot \mathrm{H} \cdot \mathrm{A}\right]^{+}\right)(\mathrm{X}=\mathrm{H}, \mathrm{D})$. Each of these adducts was isolated and submitted to CID (normalized collision energy: $14 \%$ and $17 \%$ ) by collisions with $\mathrm{He}$ gas into the trap (nominal pressure, $1.4 \times 10^{-5}$ Torr; activation time $=30 \mathrm{~s}$; activation $\mathrm{Q}=$ 0.20 ). The relative abundance of fragments was determined from the intensity of the relevant peaks acquired in centroid mode. In each acquisition, the final spectrum is the average of about 40 scans, each consisting of two microscans. Standard deviation of relative ion abundances: $\pm 10 \%$.

\section{ESI-FT-ICR Experiments}

The experiments were carried out at room temperature in an APEX II FT-ICR mass spectrometer fit with an ESI source (Apollo; Bruker, Milan, Italy) and a resonance cell ("infinity cell") located between the poles of a superconducting magnet (4.7 T). Stock methanolic solutions of $\boldsymbol{M}^{\mathbf{H}}\left(1 \times 10^{-5} \mathrm{M}\right)$, each containing a 2-fold excess of the nucleoside (A) were electrosprayed through a heated capillary $\left(130{ }^{\circ} \mathrm{C}\right)$ into the external source of a FT-ICR mass spectrometer. The resulting ions were transferred into the resonance cell by using of a system of potentials and lenses and were quenched by collision with argon pulsed into the cell through a magnetic valve. ESI of $\boldsymbol{M} / \mathrm{A}$ methanolic solutions leads to the formation of abundant signals, corresponding to the proton-bound $\left[\boldsymbol{M}^{\mathbf{H}} \cdot \mathrm{H} \cdot \mathrm{A}\right]^{+}$and $\left[\boldsymbol{M}^{\mathbf{H}}{ }_{2} \cdot \mathrm{H} \cdot \mathrm{A}\right]$ ${ }^{+}$complexes. Both of them were monitored and isolated by broad-band ejection of the accompanying ions. The $\left[\boldsymbol{M}^{\mathrm{H}} \cdot \mathrm{H} \cdot \mathrm{A}\right]^{+}$ or $\left[\boldsymbol{M}^{\mathrm{H}}{ }_{2} \cdot \mathrm{H} \cdot \mathrm{A}\right]^{+}$were allowed to react with the chiral amine B present in the cell at a fixed pressure, whose value ranged from $8.0 \times 10^{-9}$ to $4.0 \times 10^{-8}$ mbar depending upon its reactivity.

\section{Results and Discussion}

\section{ESI-IT-MS Experiments}

At two selected collision energies (14\% and $17 \%$ values of normalized collision energy), the CID of the proton-bound homochiral $\left[\boldsymbol{M}_{2}^{\mathbf{X}}{ }_{2} \cdot \mathrm{H} \cdot \mathrm{A}\right]^{+}$complexes yield the corresponding $\left[\boldsymbol{M}^{\mathbf{X}}{ }_{2} \cdot \mathrm{H}\right]^{+}$and $\left[\boldsymbol{M}^{\mathbf{X}} \cdot \mathrm{H} \cdot \mathrm{A}\right]^{+}$fragments. A small amount of $\left[\boldsymbol{M}^{\mathbf{X}} \cdot \mathrm{H}\right]^{+}$has been observed as a minor dissociation product never exceeding $7 \%$ of the relative abundance (with the only exception of $\left[\boldsymbol{M}^{\mathbf{X}}{ }_{2} \cdot \mathrm{H} \cdot \mathbf{d C}\right]^{+}$where such percentage reaches $20 \%$ ) (Scheme 1). The MS/MS experiments of $\left[\boldsymbol{M}^{\mathbf{X}}{ }_{2} \cdot \mathbf{H} \cdot \mathbf{d C}\right]^{+}$ aggregates yields also a not negligible amount of $\left[\boldsymbol{M}^{\mathbf{X}}{ }_{2} \cdot \mathrm{H} \cdot \mathrm{A}^{\prime}\right]^{+}$ product $\left(\mathrm{A}^{\prime}=\right.$ cytosine; $\left.7.9 \% \div 19.2 \%\right)$. The relative abundance of fragments is reported as Supporting Material (Tables S1-S4).

The main results concerning the CID of $\left[\boldsymbol{M}^{\mathrm{X}}{ }_{2} \cdot \mathrm{H} \bullet \mathrm{A}\right]^{+}(\boldsymbol{M}=\boldsymbol{R}$, $\boldsymbol{S} ; \mathrm{X}=\mathrm{H}, \mathrm{D}$ ) are summarized in Figure 2, where $\eta_{\mathrm{R}}{ }^{\mathrm{H}}$ corresponds to the $\left[\boldsymbol{R}^{\mathbf{H}} \cdot \mathrm{H} \cdot \mathrm{A}\right]^{+} /\left[\boldsymbol{R}^{\mathbf{H}}{ }_{2} \cdot \mathrm{H}\right]^{+}$fragmentation ratio from

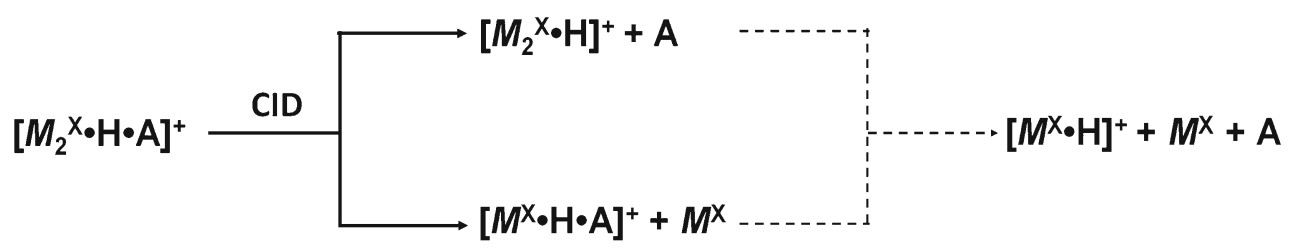

Scheme 1. Fragmentation branching of the $\operatorname{CID}\left[\boldsymbol{M}^{\mathbf{x}}{ }_{2} \bullet \mathrm{H} \bullet A\right]^{+}$complexes. The dotted lines and arrows indicate the minor fragmentation channel 

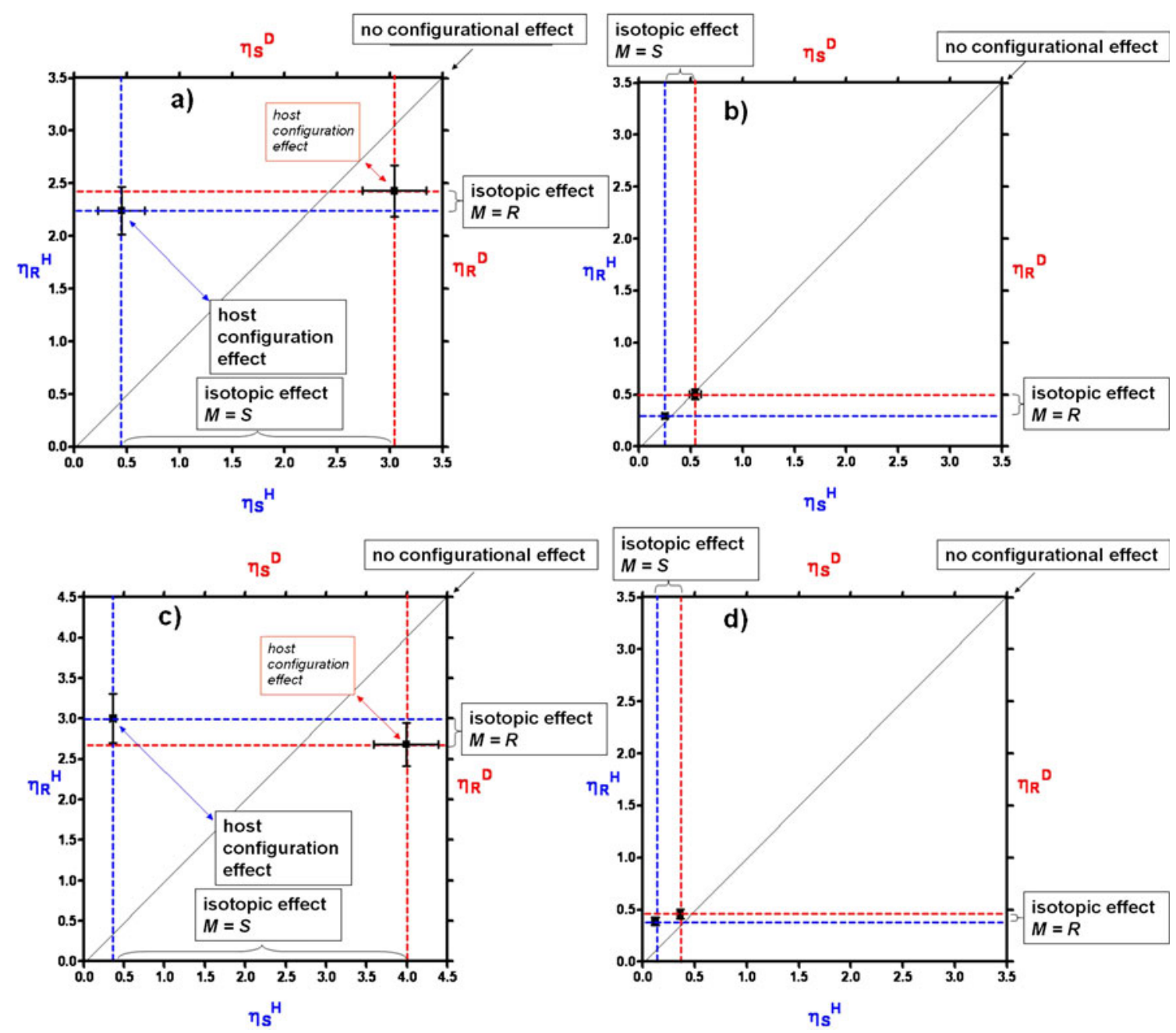

Figure 2. CID results of the $\left[\boldsymbol{M}^{\mathrm{X}}{ }_{2}{ }^{\bullet} \mathrm{H} \bullet A\right]^{+}$complexes. (a) $A=\mathbf{d C}$; (b) $A=\mathbf{C}$; (c) $A=$ ara-C; (d) $A=\mathbf{G}$. $\eta_{R}{ }^{H}$ corresponds to the $\left[\boldsymbol{R}^{\mathrm{H} \bullet H \bullet A}\right]^{+} /\left[\boldsymbol{R}^{\mathrm{H}}{ }_{2} \bullet \mathrm{H}\right]^{+}$fragmentation ratio from $\left[\boldsymbol{R}^{\mathrm{H}}{ }_{2} \bullet \mathrm{H} \bullet \mathrm{A}\right]^{+}, \eta_{S}{ }^{\mathrm{H}}$ corresponds to the $\left[\boldsymbol{S}^{\mathrm{H}} \bullet \mathrm{H} \bullet \mathrm{A}\right]^{+} /\left[\mathbf{S}^{\mathrm{H}}{ }_{2} \bullet \mathrm{H}\right]^{+}$ratio from $\left[\mathbf{S}^{\mathrm{H}}{ }_{2} \bullet \mathrm{H}^{\circ} \mathrm{A}\right]^{+}, \eta_{R}{ }^{\mathrm{D}}$ to

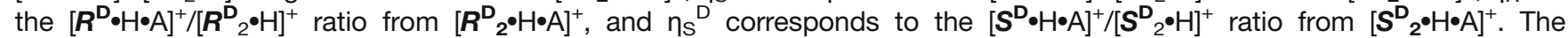
deviations from the unity slope line are proportional to the fragmentation enantioselectivity measured for $\left[\boldsymbol{M}^{\mathrm{H}} \mathbf{2}^{\bullet} \mathrm{H}^{\circ} \mathrm{A}\right]^{+}$(the blue double arrowed line) and $\left[M^{\mathrm{D}}{ }_{2} \bullet \mathrm{H} \bullet \mathrm{A}\right]^{+}$(the red double arrowed line). Furthermore, the distances between the blue and the red broken lines on the $x$ - and $y$-axis are related to the isotope effect in the CID of the $\left[\mathbf{S}^{\mathbf{X}}{ }_{2} \bullet H^{\bullet} \mathrm{A}\right]^{+}(\mathrm{X}=\mathrm{H}, \mathrm{D})$ and $\left[\boldsymbol{R}^{\mathbf{X}}{ }_{2} \bullet \mathrm{H}^{\bullet} \mathrm{A}\right]^{+}(\mathrm{X}=\mathrm{H}, \mathrm{D})$, respectively

$\left[\boldsymbol{R}^{\mathbf{H}} \cdot{ }_{2} \cdot \mathrm{H} \cdot \mathrm{A}\right]^{+}, \eta_{\mathrm{S}}{ }^{\mathrm{H}}$ corresponds to the $\left[\boldsymbol{S}^{\mathbf{H}} \cdot \mathrm{H} \cdot \mathrm{A}\right]^{+} /\left[\boldsymbol{S}^{\mathbf{H}}{ }_{2} \cdot \mathrm{H}\right]^{+}$ratio from $\left[\boldsymbol{S}_{\mathbf{2}^{\mathbf{H}}} \cdot \mathrm{H} \cdot \mathrm{A}\right]^{+}, \eta_{\mathrm{R}}^{\mathrm{D}}$ to the $\left[\boldsymbol{R}^{\mathbf{D}} \cdot \mathrm{H} \cdot \mathrm{A}\right]^{+} /\left[\boldsymbol{R}^{\mathbf{D}}{ }_{2} \cdot \mathrm{H}\right]^{+}$ratio from $\left[\boldsymbol{R}^{\mathbf{D}}{ }_{2} \cdot \mathrm{H} \cdot \mathrm{A}\right]^{+}$, and $\eta_{\mathrm{S}}{ }^{\mathrm{D}}$ corresponds to the $\left[\boldsymbol{S}^{\mathbf{D}} \cdot \mathrm{H} \cdot \mathrm{A}\right]^{+} /\left[\boldsymbol{S}^{\mathbf{D}}{ }_{2} \cdot \mathrm{H}\right]^{+}$ ratio from $\left[\boldsymbol{S}^{\mathbf{D}}{ }_{\mathbf{2}} \cdot \mathrm{H} \cdot \mathrm{A}\right]^{+}$. The unity slope line represents no effects of the host configuration in the $\left[\boldsymbol{M}^{\mathbf{X}}{ }_{2} \cdot \mathrm{H} \cdot \mathrm{A}\right]^{+}(\boldsymbol{M}=\boldsymbol{R}, \boldsymbol{S}$; $\mathrm{X}=\mathrm{H}, \mathrm{D})$ fragmentation. The deviations from this line are proportional to the fragmentation enantioselectivity measured for $\left[\boldsymbol{M}^{\mathbf{H}} \cdot{ }_{2} \cdot \mathrm{H} \cdot \mathrm{A}\right]^{+}$(the blue double arrowed line) and $\left[\boldsymbol{M}_{\mathbf{2}}^{\mathbf{D}} \cdot \mathrm{H} \cdot \mathrm{A}\right]$ ${ }^{+}$(the red double arrowed line). Furthermore, the distances between the blue and the red broken lines on the $x$-and $y$-axis are related to the isotope effect in the CID of the $\left[\boldsymbol{S}_{2}{ }_{2} \cdot \mathrm{H} \bullet \mathrm{A}\right]^{+}(\mathrm{X}$ $=\mathrm{H}, \mathrm{D})$ and $\left[\boldsymbol{R}^{\mathbf{X}}{ }_{2} \cdot \mathrm{H} \bullet \mathrm{A}\right]^{+}(\mathrm{X}=\mathrm{H}, \mathrm{D})$ respectively. The deviation from the unity slope line indicates that the host configuration plays a greater role in the $\left[\boldsymbol{M}^{\mathbf{H}}{ }_{2} \cdot \mathrm{H} \cdot \mathbf{d C}\right]^{+}(\mathrm{m} / z=1716.69 \mathrm{u})$ fragmentation than in the $\left[\boldsymbol{M}^{\mathbf{D}}{ }_{\mathbf{2}} \cdot \mathbf{H} \cdot \mathbf{d C}\right]^{+}(\mathrm{m} / \mathrm{z}=1728.76 \mathrm{u})$ one (Figure 2a). Moreover, a significant isotope effect is observed in the $\left[\mathbf{S}^{\mathbf{X}}{ }_{2} \cdot \mathbf{H} \cdot \mathbf{d C}\right]^{+}$fragmentation (distance between the blue and the red dotted lines along the $\mathrm{x}$-axis), whereas the effect is much less clearly discernible in the $\left[\boldsymbol{R}_{2}^{\mathbf{X}}{ }_{2} \cdot \mathbf{H} \cdot \mathbf{d C}\right]^{+}$one distance between the blue and the red dotted lines along the y-axis). Plots analogous to that of Figure 2a are reported in Figure 2b,c, $\mathrm{d}$ for $\left[\boldsymbol{M}^{\mathbf{X}}{ }_{2} \cdot \mathrm{H} \cdot \mathrm{A}\right]^{+}(\mathrm{A}=\mathbf{C}$, ara-C, $\mathbf{G})$, respectively. Fragmentation of $\left[\boldsymbol{M}^{\mathbf{X}}{ }_{2} \cdot \mathrm{H} \cdot \text { ara-C }\right]^{+}(\mathrm{X}=\mathrm{H}: m / z=1732.69 \mathrm{u} ; \mathrm{X}=\mathrm{D}: m / z=$ $1744.76 \mathrm{u}$ ) show the same host configuration and isotope effects of $\left[\boldsymbol{M}^{\mathbf{H}}{ }^{\bullet} \cdot \mathrm{H} \cdot \mathbf{d C}\right]^{+}$(Figure 2c). Incidentally, the H/D isotope effect in these systems seems fully offset by the opposite $S / R$ configuration effect, both being relatively large in the hydrogenated adducts and relatively small in the deuterated analogues (Figure 3).

Compared with the homochiral $\left[\boldsymbol{M}_{2}^{\mathbf{X}} \cdot \mathrm{H} \cdot \mathrm{A}\right]^{+}$complexes, their heterochiral $\left[\boldsymbol{M}^{\mathbf{H}} \cdot \boldsymbol{M}^{\mathbf{D}} \cdot \mathrm{H} \cdot \mathrm{A}\right]^{+}$analogues lose the neutral guest, rather than the second host molecule $(0.19>\eta>0.4$; A 


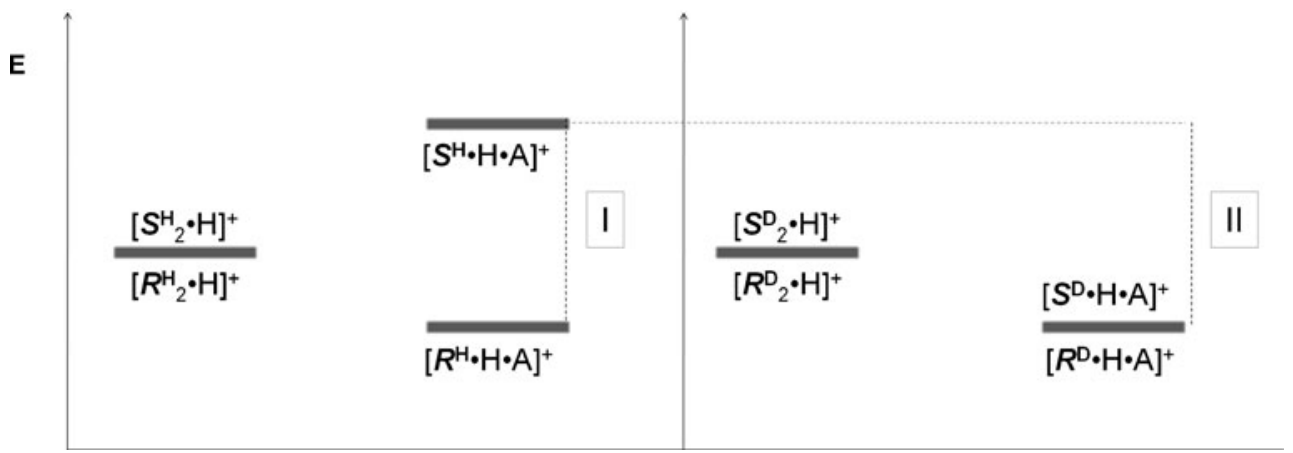

Figure 3. Energetic diagram obtained from the CID of the $\left[\mathbf{M}^{\mathbf{X}}{ }_{2^{\bullet}} \mathrm{H} \bullet \mathrm{A}\right]^{+}$complexes $(\mathrm{A}=\mathbf{d C}$ and ara-C)

$=\mathbf{d C}$, ara-C). This behavior is more pronounced in the other studied complexes $(0.024>\eta>0.067 ; \mathrm{A}=\mathbf{C}, \mathbf{G})$. More interesting is the observation that the fragmentation of $\left[\boldsymbol{M}^{\mathrm{H}} \cdot \boldsymbol{M}^{\mathbf{D}} \cdot \mathrm{H} \cdot \mathrm{A}\right]^{+}$ $\left(\mathrm{A}=\mathbf{d C}\right.$, ara-C) gives rise to a $\left[S^{\mathbf{D}} \cdot \mathrm{H} \cdot \mathrm{A}\right]^{+} /\left[S^{\mathrm{H}} \cdot \mathrm{H} \cdot \mathrm{A}\right]^{+}$ratio of $1.5 \pm 0.1$, while the $\left[\boldsymbol{R}^{\mathbf{D}} \cdot \mathrm{H} \cdot \mathrm{A}\right]^{+} /\left[\boldsymbol{R}^{\mathrm{H}} \cdot \mathrm{H} \cdot \mathrm{A}\right]^{+}$one is $0.87 \pm 0.05$. Such a difference supports the hypothesis of a differential thermodynamic stabilization of the complexes, due to the presence of hydrogen in place of deuterium atoms, which can be related to the isotope effect observed in the fragmentation of the homochiral $\left[\boldsymbol{S}^{\mathbf{X}}{ }_{2} \cdot \mathrm{H} \bullet \mathrm{A}\right]^{+}(\mathrm{X}=\mathrm{H}, \mathrm{D} ; \mathrm{A}=\mathbf{d C}$, ara-C) complexes. The similar relative abundance of $\left[\boldsymbol{R}^{\mathbf{D}} \cdot \mathrm{H} \cdot \mathrm{A}\right]^{+}$and $\left[\boldsymbol{R}^{\mathrm{H}} \cdot \mathrm{H} \cdot \mathrm{A}\right]^{+}(\mathrm{A}=\mathbf{d C}$, ara-C) accounts for the lack of any significant isotope effect. The most remarkable aspect regards the CID difference between the complexes with $\mathbf{C}$ and ara-C, since these molecules are epimers characterized by the same 2'substituent, but oriented in opposite direction relative to the furanose ring.

It should be noted, in this connection, that fragmentation of $\left[\boldsymbol{M}^{\mathbf{H}} \cdot \boldsymbol{M}^{\mathbf{D}} \cdot \mathrm{H} \cdot \mathrm{A}\right]^{+}(\mathrm{A}=\mathbf{C}, \mathbf{G})$ gives rise to $\left[\boldsymbol{S}^{\mathbf{D}} \cdot \mathrm{H} \cdot \mathrm{A}\right]^{+} \sim\left[\boldsymbol{S}^{\mathbf{H}} \cdot \mathrm{H} \cdot \mathrm{A}\right]^{+}$that could explain the lack of any significant isotope effect on the fragmentation of their homochiral $\left[\boldsymbol{S}_{2}{ }_{2} \bullet \mathrm{H} \bullet \mathrm{A}\right]^{+}(\mathrm{X}=\mathrm{H}, \mathrm{D} ; \mathrm{A}=\mathbf{C}, \mathbf{G})$ precursors. Unfortunately, the large error associated to the integration of the definitely low signals of the relative peaks did not

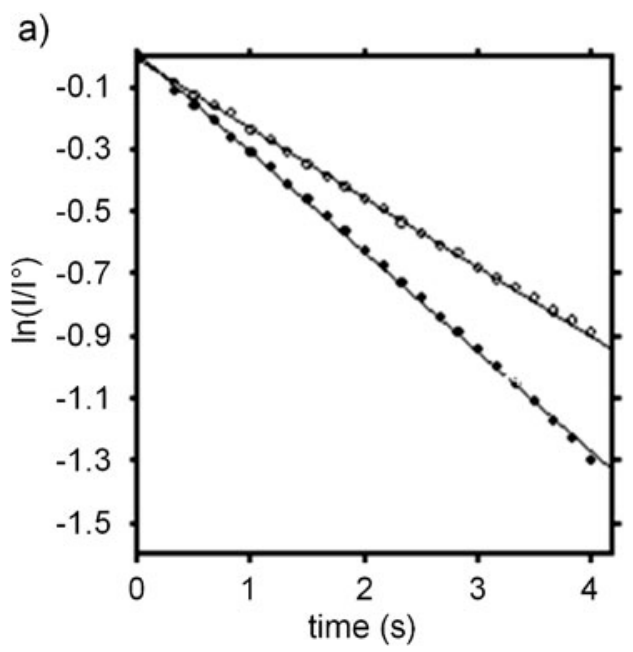

allow to confirm this hypothesis for the value of ratio $\left[\boldsymbol{R}^{\mathbf{D}} \cdot \mathrm{H} \cdot \mathbf{G}\right]^{+} /\left[\boldsymbol{R}^{\mathrm{H}} \cdot \mathrm{H} \cdot \mathbf{G}\right]^{+}$.

\section{ESI-FT-ICR Experiments}

With the aim to outline a comprehensive study of the tetramide/nucleosides interaction, we performed a complete ESI-FT-ICR investigation of the reactivity of the ESI-formed $\left[\boldsymbol{M}^{\mathbf{H}}{ }_{\mathbf{n}} \cdot \mathrm{H} \cdot \mathrm{A}\right]^{+}$complexes $(\mathrm{n}=1,2)$ versus $(R)-(-)$-but-2-ylamine $\left(\mathrm{B}_{\mathrm{R}}\right)$ or $(S)-(+)$-but-2-ylamine $\left(\mathrm{B}_{\mathrm{S}}\right)$ [12-17]. The studied reaction leads to the exclusive formation of the guest-addition products $\left[\boldsymbol{M}^{\mathbf{H}} \cdot \mathbf{n} \cdot \mathrm{H} \cdot \mathrm{A} \cdot \mathrm{B}\right]^{+}$.

The linear plots observed in the reactions between the $\mathrm{B}$ enantiomers and $\left[\boldsymbol{M}^{\mathbf{H}}{ }_{\mathbf{n}} \cdot \mathrm{H} \cdot \mathrm{A}\right]^{+}(\mathrm{A}=\mathbf{C}, \mathbf{G} ; \mathbf{n}=1,2)$ denotes the occurrence of the irreversible uptake of the amine $\mathrm{B}$ (Figure 4a). In contrast, the curvilinear plots (Figure 4b), observed in the reactions between the $\mathrm{B}$ enantiomers and $\left[\boldsymbol{M}^{\mathbf{H}}{ }_{\mathbf{n}} \cdot \mathrm{H} \cdot \mathrm{A}\right]^{+}(\mathrm{A}=\mathbf{d C}$, ara-C; $\mathrm{n}=1,2)$, are consistent with the reversible addition of the amine. In order to confirm the reversibility of the B addition to the $\left[\boldsymbol{M}^{\mathbf{H}}{ }_{\mathbf{n}} \cdot \mathrm{H} \cdot \mathbf{d C}\right]^{+}$and $\left[\boldsymbol{M}^{\mathbf{H}} \cdot \mathbf{H} \cdot \text { ara-C }\right]^{+}$aggregates, the following experiment has been set up (Scheme 2): the $\left[\boldsymbol{M}^{\mathbf{H}}{ }_{\mathbf{n}} \cdot \mathrm{H} \cdot \mathrm{A}\right]^{+}(\mathrm{n}=1,2)$ complexes were allowed to react with $\mathrm{B}$ for an adequate delay time (I) to generate a significant amount of the

b)

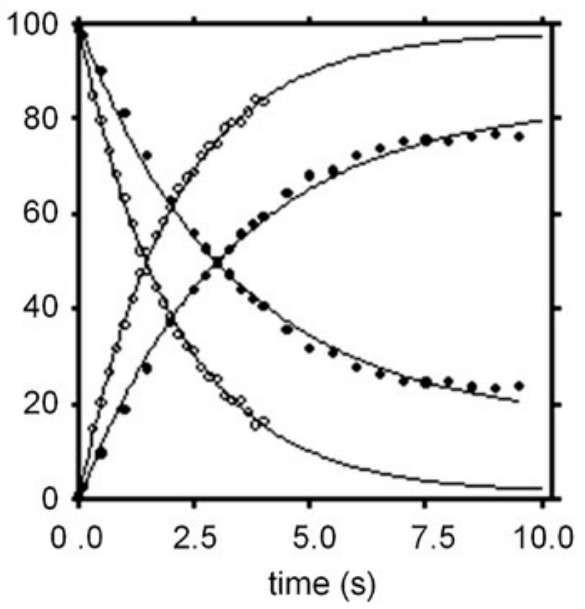

Figure 4. Kinetic plot of the reaction of $\left[\boldsymbol{M}^{\mathrm{H}} \bullet \mathrm{H} \bullet \mathrm{A}\right]^{+}$with $(S)-(+)-\sec$-butylamine. (a) $\mathrm{A}=\mathbf{G}$, open circle $\boldsymbol{M}=\boldsymbol{R}$, full circle $\boldsymbol{M}=\mathbf{S}$; (b) A =dC, open circle $\boldsymbol{M}=\boldsymbol{S}$, full circle $\boldsymbol{M}=\boldsymbol{R}$ 


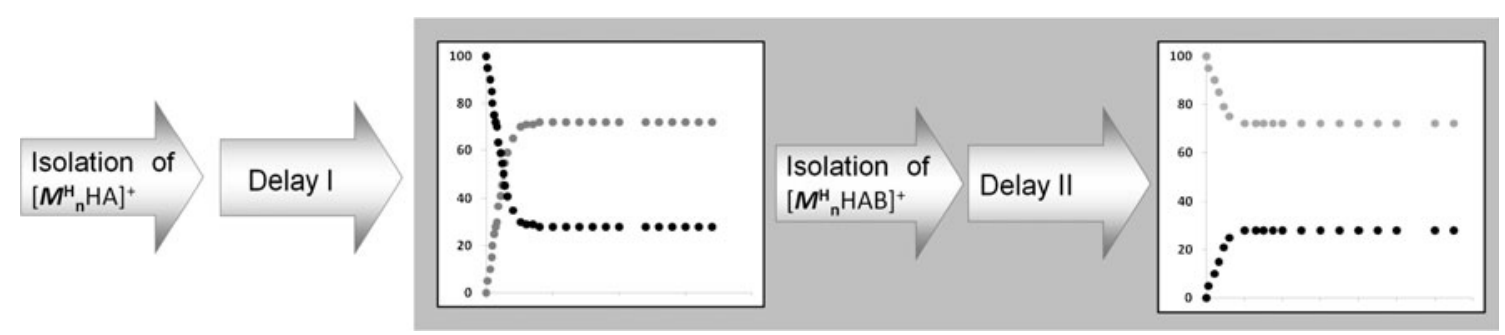

Scheme 2. Layout of standard kinetic FT-ICR (Delay I) followed by the equilibrium test on the re-isolated reaction product (Delay II)

$\left[\boldsymbol{M}^{\mathbf{H}} \cdot \mathrm{H} \cdot \mathrm{A} \cdot \mathrm{B}\right]^{+}$products. Then, the adduct was isolated under the same experimental conditions and allowed to react for a second delay time (II), until it reached approximately the same equilibrium $\left[\boldsymbol{M}_{\mathbf{n}}^{\mathbf{H}} \cdot \mathrm{H} \cdot \mathrm{A} \cdot \mathrm{B}\right]^{+} /\left[\boldsymbol{M}_{\mathbf{n}}^{\mathbf{H}} \cdot \mathrm{H} \cdot \mathrm{A}\right]^{+}$ratio previously measured. On this ground, the following kinetic scheme is proposed for the reaction with the $\left[\boldsymbol{M}^{\mathbf{H}}{ }_{\mathbf{n}} \cdot \mathbf{H} \cdot \mathbf{d C}\right]^{+}$ and $\left[\boldsymbol{M}_{\mathbf{n}}^{\mathbf{H}} \cdot \mathbf{H} \cdot \mathbf{a r a}-\mathbf{C}\right]^{+}$complexes [18].

$$
\left[M^{\mathbf{H}}{ }_{\mathbf{n}} \bullet \mathrm{H} \bullet \mathrm{A}\right]^{+}+\mathrm{B} \leftrightarrows\left[M^{\mathbf{H}}{ }_{\mathrm{n}} \bullet \mathrm{H} \bullet \mathrm{A} \bullet \mathrm{B}\right]^{+} \quad \mathrm{n}=1,2
$$

The rate constant of the forward bimolecular step is denoted as $k_{1}$, while that of the unimolecular adduct dissociation as $k_{-1}\left(k_{-1}\right.$ is negligible for $\left.\mathrm{A}=\mathbf{C}, \mathbf{G}\right)$. The pseudo-first-order rate constant $k_{1}^{\prime}=k_{1}$ [B] was derived by best-fitting on equation $2 \mathrm{a}, 2 \mathrm{~b}$ [19] the relative abundance of the $\left[\boldsymbol{M}_{\mathbf{n}}^{\mathbf{H}} \cdot \mathrm{H} \cdot \mathrm{A} \cdot \mathrm{B}\right]^{+}(\mathbf{n}=1,2)$ ions as a function of the delay time $t$ (the solid lines in Figure 4), using as the only constraint the $K_{e q}=k_{1}^{\prime} / k_{-1}=\left[\boldsymbol{M}_{\mathbf{n}}^{\mathbf{H}} \cdot \mathrm{H} \bullet \mathrm{A} \bullet \mathrm{B}\right]^{+} /\left(\left[\boldsymbol{M}_{\mathbf{n}}^{\mathbf{H}} \cdot \mathrm{H} \bullet \mathrm{A}\right]^{+}[\mathrm{B}]\right.$

Table 1. Measured Rate Constants for the Reaction of $\left[\boldsymbol{M}_{\mathbf{n}}^{\mathbf{H}} \cdot \mathrm{H} \cdot \mathrm{A}\right]^{+}$ Complexes $(\mathrm{n}=1,2)$ with $(S)-(+)-$ sec-Butylamine

\begin{tabular}{|c|c|c|c|}
\hline Guest (A) & Complex & $k_{1}^{\mathrm{a}}$ & $k_{-1}\left(s^{-1}\right)$ \\
\hline G & {$\left[\boldsymbol{R}^{\mathbf{H}} \cdot \mathrm{H} \cdot \mathrm{A}\right]^{+}$} & $2.11 \pm 0.207$ & \\
\hline $\mathbf{G}$ & {$\left[\boldsymbol{S}^{\mathbf{H}} \cdot \mathrm{H} \cdot \mathrm{A}\right]^{+}$} & $2.17 \pm 0.211$ & \\
\hline & & $\rho^{b}=0.97 \pm 0.13$ & \\
\hline G & {$\left[R_{2}{ }^{\mathrm{H}} \cdot \mathrm{H} \cdot \mathrm{A}\right]^{+}$} & $1.33 \pm 0.128$ & \\
\hline G & {$\left[\mathrm{S}_{2}{ }^{\mathrm{H}} \cdot \mathrm{H} \cdot \mathrm{A}\right]^{+}$} & $\begin{array}{c}2.17 \pm 0.197 \\
\mathbf{0}^{\boldsymbol{b}}=\mathbf{0 . 6 1} \pm \mathbf{0 . 0 8}\end{array}$ & \\
\hline $\mathrm{C}$ & {$\left[\boldsymbol{R}^{\mathrm{H}} \cdot \mathrm{H} \cdot \mathrm{A}\right]^{+}$} & $\begin{array}{c}\mathbf{p}-\mathbf{0 . 0 1} \pm \mathbf{0 . 0 0} \\
1.97 \pm 0.232\end{array}$ & \\
\hline C & {$\left[\boldsymbol{S}^{\mathbf{H}} \cdot \mathrm{H} \cdot \mathrm{A}\right]^{+}$} & $\begin{array}{c}2.46 \pm 0.266 \\
\boldsymbol{p}^{\boldsymbol{b}}=\mathbf{0 . 8 0} \pm \mathbf{0 . 1 3}\end{array}$ & \\
\hline $\mathrm{C}$ & {$\left[R_{0}{ }^{\mathrm{H}} \cdot \mathrm{H} \cdot \mathrm{A}\right]^{+}$} & $1.78 \pm 0.204$ & \\
\hline C & {$\left[S_{2}{ }^{\mathrm{H}} \cdot \mathrm{H} \cdot \mathrm{A}\right]^{+}$} & $\begin{array}{c}1.38 \pm 0.152 \\
\boldsymbol{\rho}^{\boldsymbol{b}}=\mathbf{1 . 2 9} \pm \mathbf{0 . 2 0}\end{array}$ & \\
\hline ara-C & {$\left[\boldsymbol{R}^{\mathrm{H}} \cdot \mathrm{H} \cdot \mathrm{A}\right]^{+}$} & $1.17 \pm 0.108$ & $0.1132 \pm 0.0117$ \\
\hline ara-C & {$\left[\boldsymbol{S}^{\mathbf{H}} \cdot \mathrm{H} \cdot \mathrm{A}\right]^{+}$} & $\begin{array}{r}0.7738 \pm 0.078 \\
\boldsymbol{\rho}^{\boldsymbol{b}}=\mathbf{1 . 5 1} \pm \mathbf{0 . 2 1}\end{array}$ & $\begin{array}{c}0.1543 \pm 0.0180 \\
\boldsymbol{\rho}^{\boldsymbol{b}}=\mathbf{0 . 7 3} \pm \mathbf{0 . 1 1}\end{array}$ \\
\hline ara-C & {$\left[R_{2}{ }^{\mathrm{H}} \cdot \mathrm{H} \cdot \mathrm{A}\right]^{+}$} & $1.874 \pm 0.106$ & $0.2191 \pm 0.0134$ \\
\hline ara-C & {$\left[\mathrm{S}_{2} \mathrm{H} \cdot \mathrm{H} \cdot \mathrm{A}\right]^{+}$} & $\begin{array}{c}2.589 \pm 0.092 \\
\boldsymbol{b}^{\boldsymbol{b}}=\mathbf{0 . 7 2} \pm \mathbf{0 . 0 5}\end{array}$ & $\begin{array}{c}0.0618 \pm 0.0025 \\
\mathbf{p}^{\boldsymbol{b}}=\mathbf{3 . 5 4} \pm \mathbf{0 . 2 6}\end{array}$ \\
\hline $\mathrm{dC}$ & {$\left[\boldsymbol{R}^{\mathbf{H}} \cdot \mathrm{H} \cdot \mathrm{A}\right]^{+}$} & $0.994 \pm 0.045$ & $0.0954 \pm 0.0142$ \\
\hline $\mathrm{dC}$ & {$\left[\boldsymbol{S}^{\mathbf{H}} \cdot \mathrm{H} \cdot \mathrm{A}\right]^{+}$} & $\begin{array}{c}0.345 \pm 0.012 \\
\boldsymbol{\rho}^{\boldsymbol{b}}=\mathbf{2 . 8 8} \pm \mathbf{0 . 1 6}\end{array}$ & $\begin{array}{c}0.0495 \pm 0.0055 \\
\mathbf{p}^{\boldsymbol{b}}=\mathbf{2 . 0 8} \pm \mathbf{0 . 3 9}\end{array}$ \\
\hline $\mathrm{dC}$ & {$\left[R_{2}{ }^{\mathrm{H}} \cdot \mathrm{H} \cdot \mathrm{A}\right]^{+}$} & $0.368 \pm 0.011$ & $0.062 \pm 0.003$ \\
\hline dC & {$\left[S_{2}{ }^{\mathrm{H}} \cdot \mathrm{H} \cdot \mathrm{A}\right]^{+}$} & $\begin{array}{c}0.267 \pm 0.021 \\
\boldsymbol{\rho}^{\boldsymbol{b}}=\mathbf{1 . 3 8} \pm \mathbf{0 . 1 2}\end{array}$ & $\begin{array}{r}0.165 \pm 0.006 \\
\rho^{b}=\mathbf{0 . 3 8} \pm \mathbf{0 . 0 2}\end{array}$ \\
\hline
\end{tabular}

${ }^{\mathrm{a}} \mathrm{k} \times 10^{-10} \mathrm{~cm}^{3}$ molecule $\mathrm{s}^{-1}$.

${ }^{b} \rho$ is the ratio between the rate constant measured for the reaction of $\left[\mathrm{R}_{\mathrm{n}}{ }^{\mathrm{H}} \cdot \mathrm{H} \bullet \mathrm{A}\right]^{+}$complex and the relevant $\left[\mathrm{S}_{\mathrm{n}}{ }^{\mathrm{H}} \cdot \mathrm{H} \cdot \mathrm{A}\right]^{+}$diastereoisomer. value, measured at long delay time. The relative rate constants are reported in Table 1.

$$
\left[M^{\mathrm{H}}{ }_{\mathrm{n}} \mathrm{HA}\right]^{+}=\frac{\left[M^{\mathrm{H}}{ }_{\mathrm{n}} \mathrm{HA}\right]_{0}{ }^{+}}{\left(\mathrm{k}_{1}^{\prime}+\mathrm{k}_{-1}\right)}\left[\mathrm{k}_{-1}+\mathrm{k}_{1}^{\prime} \mathrm{e}^{-\mathrm{t}\left(\mathrm{k}_{1}^{\prime}+\mathrm{k}_{-1}\right)}\right]
$$

$$
\left[M^{\mathrm{H}}{ }_{\mathrm{n}} \mathrm{HAB}\right]^{+}=\frac{\mathrm{k}_{1}\left[M^{\mathrm{H}}{ }_{\mathrm{n}} \mathrm{HA}\right]_{0}{ }^{+}}{\left(\mathrm{k}_{1}^{\prime}+\mathrm{k}_{-1}\right)}\left[1-\mathrm{k}_{1}^{\prime} \mathrm{e}^{-\mathrm{t}\left(\mathrm{k}_{1}^{\prime}+\mathrm{k}_{-1}\right)}\right]
$$

The reaction enantioselectivity is defined by the $\rho_{x}=$ $k_{x}{ }^{R} / k_{x}^{S}(x=1$ or -1$)$ ratio, which expresses the effect of configuration of the host on the forward $(x=1)$ and reverse $(x=-1)$ steps of equation 1 . A value of $\rho_{x}>1$ indicates that the addition of $\mathrm{B}$ to isolated complexes, or the loss from them, is faster in the $\left[\boldsymbol{R}_{\mathbf{n}}^{\mathbf{H}} \cdot \mathrm{H} \bullet \mathrm{A}\right]^{+}$than in the diastereomer $\left[\boldsymbol{S}^{\mathbf{H}}{ }_{\mathbf{n}} \cdot \mathrm{H} \bullet \mathrm{A}\right]^{+}$. Obviously the opposite is true when $\rho_{x}<1$. A value of $\rho_{x}=1$ corresponds to equal reaction rates. The enantioselectivity is significant in both directions of the reversible reactions $(\mathrm{A}=\mathbf{d C}$, ara-C), while in the other cases does not significantly diverge from unity (Table 1). Furthermore, there is substantially no difference between the results obtained with $(S)-(-)$-secbutylamine and $(R)-(-)$-sec-butylamine (not reported).

A strict correspondence is observed between the FT-ICR results and those from the IT-MS experiments. In both sets of experiments, the complexes with $\mathbf{d C}$ and ara-C show a similar behaviour, but completely different from that exhibited by the complexes with $\mathbf{C}$ and $\mathbf{G}$, as guests. The $\left[\boldsymbol{M}^{\mathbf{H}}{ }_{2} \bullet \mathrm{H} \bullet \mathrm{A}\right]^{+}$complexes $(\mathrm{A}=\mathbf{d C}$, ara-C) reversibly react with sec-butylamine in the FT-ICR, and enantioselectively

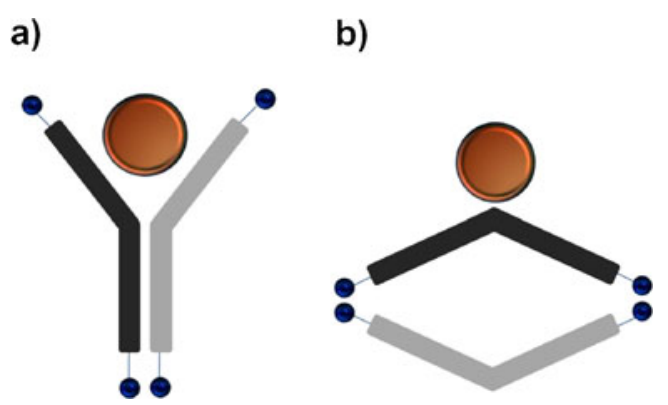

Figure 5. Schematic representation of $\left[\mathbf{M}_{\mathbf{2}} \bullet \mathrm{H} \bullet \mathrm{A}\right]^{+}$isoforms. (a) Y-shaped structures; (b) $\diamond$-isoform 
dissociate in the IT-MS environment. The other $\left[\boldsymbol{M}^{\mathbf{H}}{ }_{2} \cdot \mathrm{H} \cdot \mathrm{A}\right]^{+}$ aggregates $(\mathrm{A}=\mathbf{C}, \mathbf{G})$ neither reversibly uptake the secbutylamine, nor exhibit any chiral effect in the CID experiments. These results suggest the occurrence of two distinct isoforms of the examined supramolecules.

A possible rationalization of the mass spectrometric results can be found in the dependence on both the 2'substituent and the host's configuration of the arrangement that can be acquired from the studied supramolecules. As previously reported $[20,21]$, the three-body complexes $\left[\boldsymbol{M}_{2} \cdot \mathrm{H} \bullet \mathrm{A}\right]^{+}(\mathrm{A}=$ primary and secondary amines, ester of naphtylalanine) may tend to acquire two preferential arrangements, characterized by not very different energy: (1) the Y-shaped isoform (Y; Figure 5a), where the guest is located between the convex faces of the host molecules, and (2) the stacked-isoform ( $\diamond$; Figure 5b), where the guest interacts with the convex side of one host molecule, the second one being located on the other side. The Y-isoform has been calculated as the preferred structure for the heterochiral aggregates $\left[\boldsymbol{M}^{\mathbf{H}} \cdot \boldsymbol{M}^{\mathbf{D}} \cdot \mathrm{H} \cdot \mathrm{A}\right]^{+}$, which were found to release almost exclusively the guest $\mathrm{A}(\eta<1)$ by CID. In this perspective, the pronounced tendency of the $\left[\boldsymbol{M}^{\mathbf{X}}{ }_{2} \cdot \mathrm{H} \cdot \mathrm{A}\right]^{+}$ $(\mathrm{A}=\mathbf{C}, \mathbf{G})$ aggregates to lose preferentially $\mathrm{A}(\eta<1)$ in the CID experiments may justify the hypothesis that they are characterized by a similar $\mathbf{Y}$ supramolecular structure. In this structure, the polar group could not be strictly involved in the noncovalent interactions with the nucleoside and, thus, are relatively prone to establish intense irreversible interactions with B. The looseness of the $\mathbf{Y} /$ nucleoside interactions may also account for the small enantioselectivity and isotope effect observed.

In contrast, the significant enantioselectivities measured both in the fragmentation and in the reaction kinetics for the $\left[\boldsymbol{M}^{\mathbf{X}}{ }_{2} \cdot \mathrm{H} \cdot \mathrm{A}\right]^{+}(\mathrm{A}=\mathbf{d C}$, ara-C) aggregates suggest the occurrence of the alternative $\diamond$-isoform (Figure $5 b$ ), where the protonated amidocarbonyl of $M^{X}$ is strictly bound to the nucleoside and, thus, hardly available to accommodate irreversibly the amine B. According to this hypothesis is the fact that $\left[\boldsymbol{S}^{\mathbf{X}}{ }_{2} \cdot \mathrm{H} \cdot \mathrm{A}\right]^{+}(\mathrm{A}=\mathbf{d C}$, ara-C) display an appreciably isotope effect on the MS/MS fragmentation pattern, which could be attributed to some secondary interactions of the $-\mathrm{OCX}_{3}$ groups of the host with the functional groups of the guest (for instance one of the $\mathrm{OH}$ groups), or alternatively could be due to an allosteric effect induced by the chiral guest on the specific host-host reciprocal orientation.

Concerning the configurational effect, the ESI-IT-MS experiments indicate that $\left[\boldsymbol{R}^{\mathrm{H}} \cdot \mathrm{H} \cdot \mathrm{A}\right]^{+}$is more stable than $\left[S^{\mathbf{H}} \cdot \mathrm{H} \cdot \mathrm{A}\right]^{+}$for $\mathrm{A}=\mathbf{d C}$, ara-C, whereas they are almost equally stable when $(\mathrm{A}=\mathbf{C}$ and $\mathbf{G})$. With this in mind, the larger $K_{e q}$ constant, derived for the addition of $\mathrm{B}$ on $\left[\boldsymbol{M}^{\mathbf{H}} \cdot \mathbf{H} \cdot \mathbf{d C C}\right]^{+}$(Figure $4 \mathrm{~b}$ : the reactions on the diastereoisomeric complexes have been performed at the same pressure of B), indicates that the $\left[\boldsymbol{R}^{\mathbf{H}} \cdot \mathrm{H} \cdot \mathbf{d C}\right]^{+}$versus $\left[\boldsymbol{S}^{\mathbf{H}} \cdot \mathrm{H} \cdot \mathrm{dC}\right]^{+}$stability gap is further increased when these complexes interact with amine $\mathrm{B}$ in the corresponding
$\left[\boldsymbol{R}^{\mathbf{H}} \cdot \mathrm{H} \cdot \mathbf{d C} \cdot \mathbf{B}\right]^{+}$and $\left[\boldsymbol{S}^{\mathbf{H}} \cdot \mathbf{H} \cdot \mathbf{D} \cdot \mathbf{B}\right]^{+}$structures. This effect can be regarded as a case of enhanced enantioselectivity by monosolvation.

\section{Conclusion}

The enantioselective interactions between chiral tetra-amidic receptors and nucleosides have been investigated by the ESIIT-MS and ESI-FT-ICR-MS methodologies. Configurational effects on the CID fragmentation of diastereomeric $\left(\boldsymbol{M}^{\mathbf{H}}{ }_{2} \cdot \mathrm{H} \cdot \mathrm{A}\right)^{+}$aggregates $(\mathrm{A}=\mathbf{d C}$, ara-C) were found to be mostly offset by isotope effect in $\left(\boldsymbol{S}_{\mathbf{2}}^{\mathbf{X}} \cdot \mathbf{H} \cdot \mathrm{A}\right)^{+}(\mathrm{X}=\mathrm{H}, \mathrm{D})$. No configuration and isotope effects were discerned in the MS/ MS fragmentation of diastereomeric $\left(\boldsymbol{M}^{\mathbf{H}}{ }_{2} \cdot \mathrm{H} \cdot \mathrm{A}\right)^{+}$analogues $(\mathrm{A}=\mathbf{C}, \mathbf{G})$. This result points the involvement of two different nucleoside/tetra-amide isoforms, that can be easily ascribed to the $\mathbf{Y}$-shaped $(\mathrm{A}=\mathbf{C}$ and $\mathbf{G})$ and to the $\diamond$-isoform (dC and ara-C), on the grounds of the computational screening previously performed with several guest molecules. The structural differences of the $\left(\boldsymbol{M}^{\mathbf{H}}{ }_{2} \cdot \mathrm{H} \cdot \mathrm{A}\right)^{+}(\mathrm{A}=\mathbf{C}$ and $\mathbf{G})$ complexes versus the $\left(\boldsymbol{M}^{\mathbf{H}}{ }_{2} \cdot \mathrm{H} \bullet \mathbf{A}\right)^{+}(\mathbf{d C}$ and ara-C) ones is fully confirmed by the kinetics of their uptake of the 2-aminobutane enantiomers, measured by FT-ICR mass spectrometry. Indeed, uptake of the 2-aminobutane enantiomers by $\left[\boldsymbol{M}^{\mathbf{H}}{ }_{\mathbf{n}} \cdot \mathrm{H} \cdot \mathrm{A}\right]^{+}(\mathrm{n}=1,2 ; \mathrm{A}=\mathbf{d C}$ and ara-C) complexes is reversible, whereas that by $\left[\boldsymbol{M}^{\mathbf{H}} \cdot{ }_{\mathbf{n}} \cdot \mathrm{H} \cdot \mathrm{A}\right]^{+}(\mathrm{n}=1$, 2; $\mathbf{A}=\mathbf{C}$ and $\mathbf{G}$ ) is not. The obtained results are very encouraging in the perspective of subtle modulation of the noncovalent drug/receptor interactions, through the electronic properties of the 2'-substituent on the nucleoside furanose ring, and furthermore on its three-dimensional position. In fact, the most surprising experimental evidence concerns the different gas-phase behavior, probably corresponding to different supramolecular isoforms, between $\mathbf{C}$ and ara-C that are just epimers. This result suggests that a different guest's dipole moment (cfr. C versus ara-C) strongly influences the interaction with an amidic-pseudo-receptor, which is the simplest model of the real target of the nucleoside drugs (NTs). Indeed, two epimers could require different supramolecular arrangements of the active site of the receptor, meaning that they can allosterically induce different outputs in their protein targets.

\section{References}

1. Van Belle, H.: Role of nucleoside transport inhibition and endogenous adenosine in prevention of catecholamine induced death in rabbits. Cardiovasc. Res. 27, 68-76 (1993)

2. Baldwin, S.A., Mackey, J.R., Cass, C.E., Young, J.D.: Nucleoside transporters: molecular biology and implications for therapeutic development. Mol. Med. Today 5, 216-224 (1999)

3. Da Rocha, A.B., Lopes, R.M., Schwartsmann, G.: Natural products in anticancer therapy. Curr. Opin. Pharmacol. 1, 364-369 (2001)

4. Zhang, J., Visser, F., King, K.M., Baldwin, S.A., Young, J.D., Cass, C.E.: The role of nucleoside transporters in cancer chemotherapy with nucleoside drugs. Cancer Metastasis Rev. 26, 85-110 (2007)

5. Ruiz Van Haperen, V.W., Veerman, G., Eriksson, S., Boven, E., Stegmann, A.P., Hermsen, M., Vermorken, J.B., Pinedo, H.M., Peters, G.J.: Development and Molecular Characterization of a $2^{\prime}, 2^{\prime}$-Difluor- 
odeoxycytidine-Resistant Variant of the Human Ovarian Carcinoma. Cancer Res. 54, 4138-4143 (1994)

6. Mackey, J.R., Mani, R.S., Selner, M., Mowles, D., Young, J.D., Belt, J.A., Crawford, C.R., Cass, C.E.: Functional Nucleoside Transporters Are Required for Gemcitabine Influx and Manifestation of Toxicity in Cancer Cell Lines. Cancer Res. 58, 4349-4357 (1998)

7. Galmarini, C.M., Thomas, X., Calvo, F., Rousselot, P., Rabilloud, M., El Jaffari, A., Cros, E., Dumontet, C.: In vivo mechanisms of resistance to cytarabine in acute myeloid leukaemia. Br. J. Haematol. 117, 860868 (2002)

8. Guschlbuer, W., Jankowski, K.: Nucleoside conformation is determined by the electronegativity of the sugar substituent. Nucleic Acid Res. 8(6), 1421-1433 (1980)

9. Gasparrini, F., Pierini, M., Villani, C., Filippi, A., Speranza, M.: InducedFit in the Gas Phase: Conformational Effects on the Enantioselectivity of Chiral Tetra-Amide Macrocycles. J. Am. Chem. Soc. 130, 522-534 (2008)

10. Gasparrini, F., Misiti, D., Pierini, M., Villani, C.: A Chiral $\mathrm{A}_{2} \mathrm{~B}_{2}$ Macrocyclic Minireceptor with Extreme Enantioselectivity. Org. Lett. 4, 3993-3996 (2002)

11. Uccello-Barretta, G., Balzano, F., Martinelli, J., Berni, M.-G., Villani, C., Gasparrini, F.: NMR enantiodiscrimination by cyclic tetraamidic chiral solvating agents. Tetrahedron-Asymmetry 16, 3746-3751 (2005)

12. Botta, B., Botta, M., Filippi, A., Tafi, A., Delle Monache, G., Speranza, M.: Enantioselective Guest Exchange in a Chiral Resorcin[4]arene Cavity. J. Am. Chem. Soc. 124, 7658-7659 (2002)

13. Tafi, A., Botta, B., Botta, M., Delle Monache, G., Filippi, A., Speranza, M.: Chiral Recognition by Resorcin[4]arene Receptors: Intrinsic Kinetics and Dynamics. Chem. Eur. J. 10, 4126-4135 (2004)
14. Botta, B., Subissati, D., Tafi, A., Delle Monache, G., Filippi, A., Speranza, M.: Cavity Effects on the Enantioselectivity of Chiral Amido[4]resorcinarene Stereoisomers. Angew. Chem. 116, 4871-4874. Angew. Chem. Int. Ed. 2004, 43, 4767-4770 (2004)

15. Botta, B., Caporuscio, F., D'Acquarica, I., Delle Monache, G., Subissati, D., Tafi, A., Botta, M., Filippi, A., Speranza, M.: Gas-Phase Enantioselectivity of Chiral Amido[4]resorcinarene Receptors. Chem. Eur. J. 12, 8096-8105 (2006)

16. Botta, B., Caporuscio, F., Subissati, D., Tafi, A., Botta, M., Filippi, A., Speranza, M.: Flattened Cone 2,8,14,20-Tetrakis(L-valinamido)[4]resorcinarene: An Enantioselective Allosteric Receptor in the Gas Phase. Angew. Chem. 118, 2783-2786. Angew. Chem. Int. Ed. 2006, 45, $2717-$ 2720 (2006)

17. Gal, J.F., Stone, M., Lebrilla, C.B.: Chiral recognition of non-natural $\alpha$ amino acids. Int. J. Mass Spectrom. 222, 259-267 (2003)

18. Angelelli, F., Chiavarino, B., Crestoni, M.E., Fornarini, S.: Binding of gaseous Fe(III)-heme cation to model biological molecules: Direct association and ligand transfer reactions. J. Am. Soc. Mass Spectrom. 16, 589-598 (2005)

19. Capellos, C., Bielski, B.H.J.: Kinetic System, p. 31-33. Wiley Interscience, New York (1972)

20. Fraschetti, C., Pierini, M., Villani, C., Gasparrini, F., Levi Mortera, S., Speranza, M.: Towards enzyme-like enantioselectivity in the gas phase: conformational control of selectivity in chiral macrocyclic dimers. Chem. Commun 361, 5430-5432 (2009)

21. Fraschetti, C., Pierini, M., Villani, C., Gasparrini, F., Filippi, A., Speranza, M.: Gas-phase structure and relative stability of proton-bound homo- and heterochiral clusters of tetra-amide macrocycles with amines. Collect. Czechoslov Chem. Commun. 74(2), 275-297 (2009) 